\title{
Age-Dependent Signal Intensity Changes in the Structurally Normal Pediatric Brain on Unenhanced T1-Weighted MR Imaging
}

\author{
(D) T.F. Flood, (D) P.R. Bhatt, (D) A. Jensen, (D).A. Maloney, (D) N.V. Stence, and (DD.M. Mirsky
}

\begin{abstract}
BACKGROUND AND PURPOSE: Various pathologic and nonpathologic states result in brain parenchymal signal intensity changes on unenhanced Tl-weighted MR imaging. However, the absence of quantitative data to characterize typical age-related signal intensity values limits evaluation. We sought to establish a range of age-dependent brain parenchymal signal intensity values on unenhanced TTWI in a sample of individuals (18years of age or younger) with structurally normal brains.
\end{abstract}

MATERIALS AND METHODS: A single-center retrospective study was performed. Gadolinium-naïve pediatric patients with structurally normal MR brain imaging examination findings were analyzed ( $n=114 ; 50 \%$ female; age range, 68 days to 18 years). ROI signal intensity measurements were obtained from the globus pallidus, thalamus, dentate nucleus, pons, and frontal lobe cortex and subcortical white matter. Multivariable linear regression was used to analyze the relationship between signal intensity values and age.

RESULTS: Results demonstrated a statistically significant association between signal intensity values and linear age in all neuroanatomic areas tested, except the frontal gray matter, $(P<.01)$. There were no statistically significant differences attributable to patient sex.

CONCLUSIONS: Age-dependent signal intensity values were determined on unenhanced TIWI in structurally normal pediatric brains. Increased age correlated with increased signal intensity in all brain locations, except the frontal gray matter, irrespective of sex. The biologic mechanisms underlying our results remain unclear and may be related to chronologic changes in myelin density, synaptic density, and water content. Establishing age-dependent signal intensity parameters in the structurally normal pediatric brain will help clarify developmental aberrations and enhance gadolinium-deposition research by providing an improved understanding of the confounding effect of age.

$\mathbf{T}$ he development of the human brain is a dynamic process, which continuously changes on both a macro- and microstructural level. ${ }^{1}$ MR imaging has proved useful not only in characterizing normal morphologic brain maturation but in describing chronologic changes in cortical structure and myelination patterns. ${ }^{2-20}$ Furthermore, various pathologic and nonpathologic states are now known to result in brain parenchymal signal intensity changes on unenhanced T1WI, including gadolinium deposition. ${ }^{21-30}$ Chronologic signal intensity changes on T1WI

Received April 19, 2019; accepted after revision August 21.

From the Departments of Radiology (T.F.F., P.R.B.) and Biostatistics \& Informatics (A.J.), University of Colorado, Aurora, Colorado; and Department of Radiology (J.A.M., N.V.S., D.M.M.), University of Colorado Children's Hospital, Aurora, Colorado.

Paper previously presented as a Turbo Talk at: Annual Meeting of the American Society of Neuroradiology, April 22-27, 2017; Long Beach, California.

Please address correspondence to David M. Mirsky, MD, Department of Radiology, University of Colorado Children's Hospital, 13123 East 16th Ave, Box B125, Aurora,

CO 80045; e-mail: David.Mirsky@childrenscolorado.org

Indicates article with supplemental on-line tables.

Indicates article with supplemental on-line photos.

http://dx.doi.org/10.3174/ajnr.A6254 and myelination patterns within the cortex and subcortical white matter, corpus collosum, and various white matter tracts within the supratentorial and infratentorial brain have been well-characterized in pediatric and adult populations..$^{2-17,19,20}$ However, agedependent T1WI signal intensity alterations within the deep gray nuclei, cerebellar nuclei, and brain stem in pediatric subjects are less well-understood. Establishing signal intensity parameters on unenhanced T1WI in structurally normal pediatric brains, including within subcortical and deep cerebellar nuclei, will help clarify developmental aberrations, elucidate pathology, and enhance gadolinium-deposition research by providing an improved understanding of the confounding effect of age. Therefore, we sought to establish an expected range of age-dependent signal intensity values in specific anatomic regions in a sample of structurally normal pediatric brains on unenhanced T1WI.

\section{MATERIALS AND METHODS Participants}

This single-center, retrospective study was approved by the local institutional review board of the University of Colorado 
Table: Linear and quadratic age parameter estimates from the general linear model

\begin{tabular}{|c|c|c|c|c|c|c|}
\hline \multirow[b]{2}{*}{ ROI } & \multicolumn{3}{|c|}{ Linear Age } & \multicolumn{3}{|c|}{ Quadratic Age } \\
\hline & Estimate & $95 \% \mathrm{Cl}$ & $P$ Value & Estimate & $95 \% \mathrm{Cl}$ & $P$ Value \\
\hline Globus pallidus & 0.00900 & $0.006-0.012$ & $<.001$ & -0.00003 & -0.000041 to -0.000015 & $<.001$ \\
\hline Thalamus & 0.006 & $0.003-0.008$ & $<.001$ & -0.000017 & -0.000029 to -0.000005 & .005 \\
\hline Dentate & 0.00500 & $0.002-0.008$ & .001 & -0.000017 & -0.00003 to -0.000003 & .02 \\
\hline Frontal GM & 0.003 & $0.001-0.005$ & .01 & -0.000009 & $-0.000019-0.000001$ & .07 \\
\hline Frontal WM & 0.011 & $0.008-0.014$ & $<.001$ & -0.000038 & $-0.000053-0.000024$ & $<.001$ \\
\hline
\end{tabular}

and was compliant with the Health Insurance Portability and Accountability Act. Informed consent was waived. Pediatric patients older than 31 days and younger than 18 years who underwent an unenhanced brain MR imaging examination between January 1, 2012, and December 31, 2012, were consecutively identified from our institution's electronic medical record data base. The first 3 male and the first 3 female patients per year of life encountered in the data base who met the following criteria were included for analysis: the presence of an interpretable 3D-MPRAGE sequence; structurally normal brain per the imaging report; no history of prior exposure to gadolinium-based contrast agents; and no brain radiation, neurofibromatosis type 1 , impaired renal or hepatic function, and systemic or metabolic illness, as per review of the patient's electronic medical record (see On-line Table 1 for a complete list of MR imaging examination indications). The MPRAGE MR imaging sequence was chosen for analysis to limit variation secondary to analysis of differing imaging sequences. ${ }^{28}$ One hundred fourteen pediatric brain MR imaging examinations were analyzed, which comprised 57 male and 57 female age-matched patients (age range, 68 days to 18 years). Patient data were used from no more than 1 examination.

\section{Imaging Protocol}

All brain MR imaging examinations were performed with a $1.5 \mathrm{~T}$ whole-body MR imaging system within our institution (Avanto; Siemens, Erlangen, Germany) on 1 of 2 identical scanners. All ROI measurements were made on an unenhanced axial T1WI 3D-MPRAGE sequence created with uniform acquisition parameters $(\mathrm{TR}$ range $=1700-1800 \mathrm{~ms}, \mathrm{TE}=2.92 \mathrm{~ms}$, section thickness $=1.0 \mathrm{~mm}, \mathrm{FOV}=250 \mathrm{~mm}$, matrix $=250 \times 250$ ).

\section{Data Collection}

Measurements of signal intensity in a $5-\mathrm{mm}$ circular ROI within the globus pallidus, thalamus, dentate nucleus, pons, frontal lobe cortical gray matter, and frontal lobe subcortical white matter were performed on unenhanced axial T1WI for all patients (see On-line Figs 1-9 for representative ROI measurements). Bilateral measurements were averaged from the globus pallidus, thalamus, dentate nucleus, and frontal lobes; single measurements were obtained from the pons. All parenchymal measurements were normalized to CSF signal intensity. The measurements were acquired by 2 radiology residents; investigators were not blinded to the patient's age. Measurement screenshots were saved and reviewed by 3 attending pediatric neuroradiologists to ensure appropriate measurement location by consensus agreement. No measurement disagreements were noted. The signal intensity measurements were transcribed into software (Excel, Version 2011; Microsoft, Redmond, Washington).

\section{Statistical Analysis}

To account for the effect of CSF, we normalized all ROI signal intensities to the CSF intensity scale. Signal intensity as a function of age (in months) was investigated for all ROIs using 2 general linear models to compare linear with quadratic fits. The linear fit used the covariates of subject sex and age, while the quadratic fit included the additional covariate of squared age. The Akaike information criteria were used to determine which model provided a higher quality fit. Additionally, to determine whether there was an acute period of signal intensity change, we conducted a piecewise linear spline analysis, and if significant, a knot corresponding to the significant change in linear slope was included in the model. Ninety-five percent confidence intervals were calculated in all figures to show the variability of the average normalized signal intensity across all ages. All analyses were performed using $\mathrm{R}$ statistical and computing software (Version 3.60; http://www. r-project.org/). A Bonferroni-corrected significance value of $P<.01$ was considered indicative of a statistically significant parameter estimate.

\section{RESULTS}

The general linear model, which included a variable for quadratic age, was found to have a better fit to the data than the model that only included subject sex and linear age across all ROIs. This model fit satisfied all modeling assumptions (linearity, homoscedasticity, normality, and independence) via examination of diagnostic plots and tests. Subject sex was not found to be significantly associated with normalized signal intensity for any of the ROIs $(P>.01)$. For all ROIs, except the frontal gray matter using both models and the dentate nucleus using the quadratic model, both the linear and quadratic age parameters were statistically significant (Table). To assess whether there existed an acute period of signal intensity change in each ROI, we conducted independent piecewise linear spline analyses, with a grid search to determine the optimal placement of the knots. This analysis was conducted on the model with only subject sex and linear age. For all ROIs, the age parameter estimate was found to be significantly different at the 36-month mark; therefore, a knot, used to allow the parameter estimate to be different before and after 36 months, was included in each ROI model. A comparison of these estimates showed that for all ROIs except frontal gray matter and the dentate nucleus, the parameter estimate for age was significantly larger during the first 3 years of life (On-line Table 2), indicating an acute period of signal intensity change throughout the brain in these regions. Figures 1 and 2 illustrate the quadratic and linear 

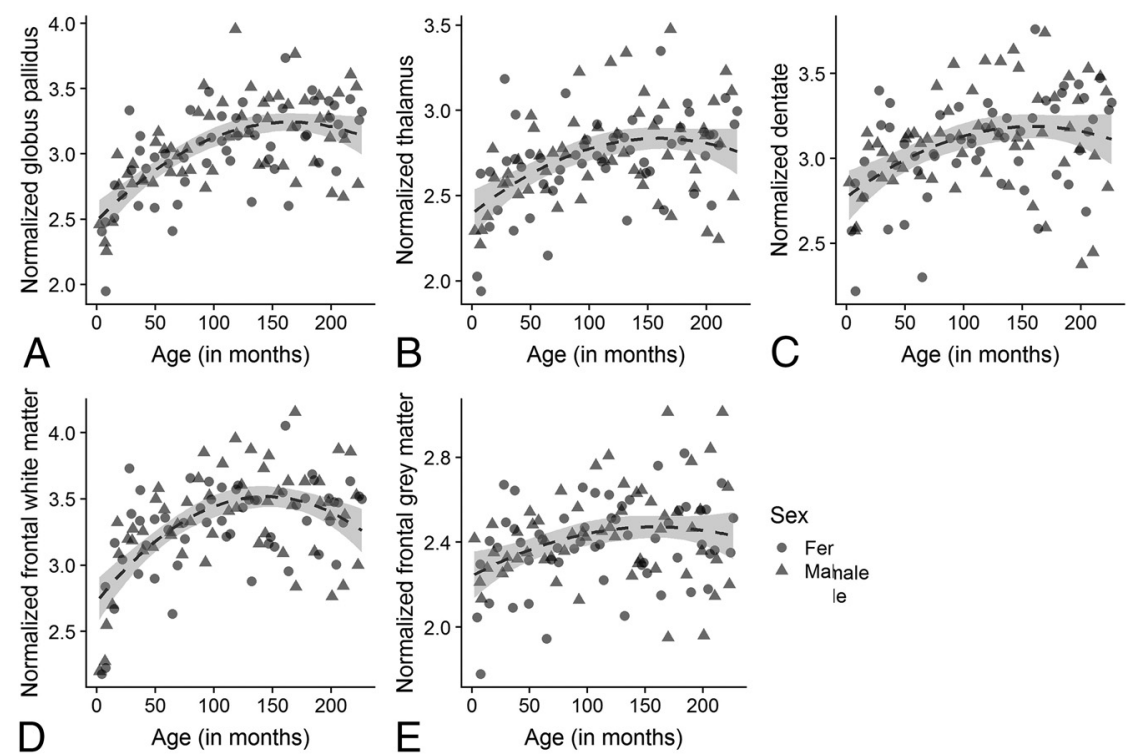

FIG 1. Multivariable linear regression with the quadratic age effect of signal intensity in the globus pallidus $(A)$, thalamus $(B)$, dentate $(C)$, frontal white matter $(D)$, and frontal gray matter $(E)$. The dashed line represents the average predicted signal intensity at each age with the gray shading representing the $95 \%$ confidence band. Points on the scatterplots are differentiated by sex.
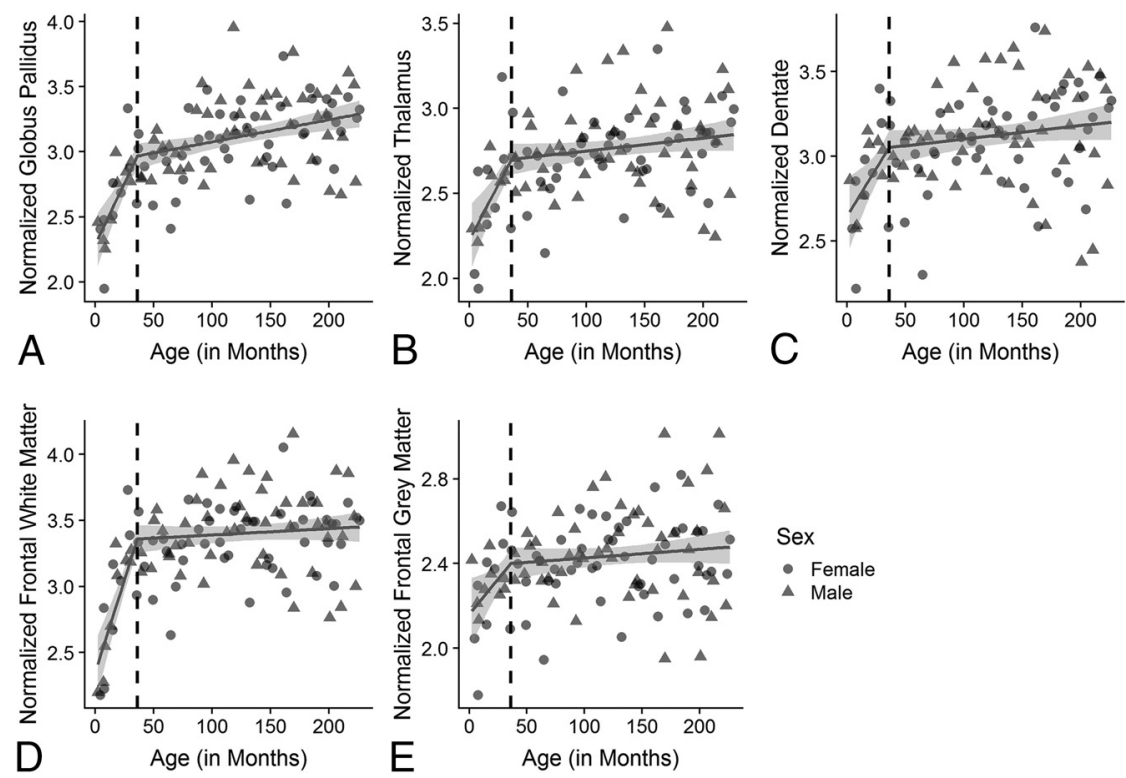

FIG 2. Multivariable linear regression of signal intensity in the globus pallidus $(A)$, thalamus $(B)$, dentate $(C)$, frontal white matter $(D)$, and frontal gray matter $(E)$, The solid line represents the average predicted signal intensity at each age with the gray shading representing the $95 \%$ confidence band. The vertical dashed line shows the location of the spline, where the effect of age on signal intensity changes. Points on the scatterplots are differentiated by sex.

spline model fits of age (in months) to normalized signal intensity for each ROI, respectively.

\section{DISCUSSION}

This study establishes a range of age-dependent signal intensity values in the structurally normal pediatric brain on unenhanced T1WI in multiple neuroanatomic areas. Increased age was associated with increased signal intensity values in all brain locations tested, except the frontal gray matter, irrespective of sex.
Furthermore, in all brain regions tested, except the frontal gray matter and the dentate nucleus, there was a statistically significant period of increased positive signal intensity change in the first 36 months of life relative to later time points. Although the frontal gray matter and dentate nucleus failed to achieve statistical significance, as above, both anatomic regions demonstrated a similar trend relative to the other regions tested. Overall, these results are in line with multiple published studies that demonstrated temporal changes in brain development on MR imaging. $^{2-20}$ Specifically, our results parallel those of multiple 
published studies showing a nonlinear positive correlation between T1WI signal intensity and age in numerous cortical areas and white matter tracts within the brain, including a similar steeper slope at earlier time points. ${ }^{10,12,16,20}$ Furthermore, our results correlate with known developmental changes in brain myelin content; however, additional less dominant factors, as listed below, likely also contributed. ${ }^{8,20}$

In the current study, by establishing age-dependent signal intensity values in the structurally normal pediatric brain on unenhanced T1WI throughout infancy to older adolescence, especially in deep gray and cerebellar nuclei, our results fill an existing gap in the literature. It is known that various pathologic and nonpathologic processes result in pediatric brain parenchymal signal intensity changes on MR imaging, such as hypoxic-ischemic injury, infection, mitochondrial or metabolic disorders, and, most recently, gadolinium deposition. ${ }^{8-14}$ Establishing brain signal intensity parameters in the structurally normal pediatric brain on unenhanced T1WI will help clarify developmental aberrations, elucidate pathology, and enhance gadolinium-deposition research by providing an improved understanding of the confounding effect of age. Specifically, these results will aid in the recognition of deviations from the expected brain parenchymal signal intensity changes, which occur throughout development. The biologic mechanisms underlying our results remain unclear and may be related to chronologic changes in myelin density, synaptic density, physiologic mineral and metal deposition, water content, and/or the glymphatic system.

Study limitations include a small single-center retrospective design and reliance on signal intensity measurements, which limit generalization of the results. T1 mapping would be more accurate to characterize T1-weighted signal intensity values, but it is not currently performed on a routine clinical basis at our institution. An additional limitation is reliance on our institution's electronic medical record to exclude prior gadolinium-based contrast material exposure; it is possible that a prior exposure was not documented in our electronic medical record.

\section{CONCLUSIONS}

Age-dependent signal intensity values in the structurally normal pediatric brain were determined on unenhanced T1-weighted MR imaging. Increased age was associated with increased signal intensity values in all brain locations tested, except the frontal gray matter, irrespective of sex. Establishing signal intensity parameters in the structurally normal pediatric brain will help clarify developmental aberrations, elucidate pathology, and enhance gadolinium-deposition research by providing an improved understanding of the confounding effect of age.

Disclosures: Thomas F. Flood-UNRELATED: Support for Travel to Meetings for the Study or Other Purposes: University of Colorado Radiology Department, Comments: Turbo Talk at the American Society of Neuroradiology 2017 annual meeting with travel expenses funded by the University of Colorado Department of Radiology.

\section{REFERENCES}

1. Kandel ER, Mack S, eds. Principles of Neural Science. 5th ed. New York: McGraw-Hill Medical; 2013
2. Salat DH, Tuch DS, Hevelone ND, et al. Age-related changes in prefrontal white matter measured by diffusion tensor imaging. Ann $\mathrm{N}$ Y Acad Sci 2005;1064:37-49 CrossRef Medline

3. Welker KM, Patton A. Assessment of normal myelination with magnetic resonance imaging. Semin Neurol 2012;32:15-28 CrossRef Medline

4. Tamnes CK, Ostby Y, Fjell AM, et al. Brain maturation in adolescence and young adulthood: regional age-related changes in cortical thickness and white matter volume and microstructure. Cereb Cortex 2010;20:534-48 CrossRef

5. Westlye LT, Walhovd KB, Dale AM, et al. Differentiating maturational and aging-related changes of the cerebral cortex by use of thickness and signal intensity. Neuroimage 2010;52:172-85 CrossRef Medline

6. Sowell ER, Thompson PM, Toga AW. Mapping changes in the human cortex throughout the span of life. Neuroscientist 2004;10:372-92 CrossRef Medline

7. Paus T, Collins DL, Evans AC, et al. Maturation of white matter in the human brain: a review of magnetic resonance studies. Brain Res Bull 2001;54:255-66 CrossRef Medline

8. Barkovich AJ, Kjos BO, Jackson DE, et al. Normal maturation of the neonatal and infant brain: MR imaging at 1.5 T. Radiology 1988;166:173-80 CrossRef Medline

9. Cho S, Jones D, Reddick WE, et al. Establishing norms for agerelated changes in proton $\mathrm{T} 1$ of human brain tissue in vivo. Magn Reson Med 1997;15:1133-43 CrossRef

10. Dean DC, O'Muircheartaigh J, Dirks H, et al. Modeling healthy male white matter and myelin development: 3 through 60 months of age. Neuroimage 2014;84:742-52 CrossRef Medline

11. Deoni SCL, Mercure E, Blasi A, et al. Mapping infant brain myelination with magnetic resonance imaging. J Neurosci 2011;31:784-91 CrossRef Medline

12. Deoni SCL, Dean DC, O'Muircheartaigh J, et al. Investigating white matter development in infancy and early childhood using myelin water faction and relaxation time mapping. Neuroimage 2012;63:1038-53 CrossRef Medline

13. Gilmore JH, Shi F, Woolson SL, et al. Longitudinal development of cortical and subcortical gray matter from birth to 2 years. Cereb Cortex 2012;22:2478-85 CrossRef Medline

14. Glasser MF, Van Essen DC. Mapping human cortical areas in vivo based on myelin content as revealed by T1- and T2-weighted MRI. J Neurosci 2011;31:11597-616 CrossRef Medline

15. Grydeland $\mathrm{H}$, Walhovd $\mathrm{KB}$, Tamnes $\mathrm{CK}$, et al. Intracortical myelin links with performance variability across the human lifespan: results from T1- and T2-weighted MRI myelin mapping and diffusion tensor imaging. J Neurosci 2013;33:18618-30 CrossRef Medline

16. O'Muircheartaigh J, Dean DC, Ginestet CW, et al. White matter development and early cognition in babies and toddlers. Hum Brain Mapp 2014;35:4475-87 CrossRef Medline

17. Shafee R, Buckner RL, Fischl B. Gray matter myelination of 1555 human brains using partial volume corrected MRI images. Neuroimage 2015;105:473-85 CrossRef Medline

18. Sowell ER, Thompson PM, Leonard CM, et al. Longitudinal mapping of cortical thickness and brain growth in normal children. $J$ Neurosci 2004;24:8223-31 CrossRef Medline

19. Travis KE, Curran MM, Torres C, et al. Age-related changes in tissue signal properties within cortical areas important for word understanding in 12- to 19-month-old infants. Cereb Cortex 2014;24:1948-55 CrossRef Medline

20. Deoni SC, Dean DC, Remer J, et al. Cortical maturation and myelination in healthy toddlers and young children. Neurorimage 2015;115:147-61 CrossRef

21. Finelli PF, Singh JU. A syndrome of bilateral symmetrical basal ganglia lesions in diabetic dialysis patients. Am J Kidney Dis 2014;63:286-88 CrossRef Medline

22. Hedge AN, Mohan S, Lath N, et al. Differential diagnosis for bilateral abnormalities of the basal ganglia and thalamus. Radiographics 2011;31:5-30 CrossRef Medline 
23. Zuccoli G, Yannes MP, Nardone R, et al. Bilateral symmetrical basal ganglia and thalamic lesions in children: an update (2015). Neuroradiology 2015;57:973-89 CrossRef Medline

24. Kanda T, Ishii $\mathrm{K}$, Kawaguchi $\mathrm{H}$, et al. High signal intensity in the dentate nucleus and globus pallidus on unenhanced T1-weighted MR images: relationship with increasing cumulative dose of a gadolinium-based contrast material. Radiology 2014;270:834-41 CrossRef Medline

25. Kanda T, Matsuda M, Oba H, et al. Gadolinium deposition after contrast-enhanced MR imaging. Radiology 2015;277:924-25 CrossRef Medline

26. Flood TF, Stence NV, Maloney JA, et al. Pediatric brain: repeated exposure to linear gadolinium-based contrast material is associated with increased signal intensity at unenhanced T1-weighted MR imaging. Radiology 2017;282:222-28 CrossRef Medline
27. Radbruch A, Weberling LD, Kieslich PJ, et al. Gadolinium retention in the dentate nucleus and globus pallidus is dependent on the class of contrast agent. Radiology 2015;275:783-91 CrossRef Medline

28. Ramalho J, Ramalho M, AlObaidy $M$, et al. T1 signal-intensity increase in the dentate nucleus after multiple exposures to gadodiamide: intraindividual comparison between 2 commonly used sequences. AJNR Am J Neuroradiol 2016;37:1427-31 CrossRef Medline

29. Blumfield E, Swenson D, Ramesh I, et al. Gadolinium-based contrast agents review of recent literature on magnetic resonance imaging signal intensity changes and tissue deposits, with emphasis on pediatric patients. Pediatr Radiol 2019;49:448-57 CrossRef Medline

30. Deike-Hofman K, Reuter J, Haase R, et al. Glymphatic pathway of gadolinium-based contrast agents through the brain overlooked and misinterpreted. Invest Radiol 2019;54:229-37 CrossRef Medline 